\title{
The Extent to Which Mathematics Teachers Implement Educational Technology Applications at the Secondary Stage from Mathematics Teachers' and Supervisors' Perspective in the South of Jordan
}

\author{
Ms. Hana Hamad Abdel Rahman Alleimon \\ Jordan - Al-Karak
}

\begin{abstract}
The study aimed to investigate the extent to which mathematics teachers implement educational technology applications in the secondary stage from the point of view of mathematics teachers and supervisors in the south of Jordan .To achieve the objective of this study, a study tool was developed and its validity and reliability was verified, then it was distributed to a sample of (116) teachers and (20) supervisors. The study concluded the following results: The extent to which mathematics teachers implement educational technology applications in the secondary stage from the mathematics teachers' perspective in south of Jordan was high, while the extent to which mathematics teachers employ educational technology applications in the secondary stage from the mathematics supervisors' perspective in south of Jordan was a medium, and the results also indicated that there were statistically significant differences at the level of significance $(\alpha \leq 0.01)$ as to the extent to which mathematics teachers employ educational technology applications in the secondary stage from the mathematics teachers' view in south of Jordan and was attributed to gender and in favor of mathematics female teachers. The variable of academic degree was in favor of post-graduate studies, while the results indicated that there were no statistically significant differences due to the years of the service variable. One of the most important recommendations was to provide government schools with educational technology applications and to train teachers to use them because they have a significant impact that is directly reflected on the student and teacher.

Keywords: Educational Technology Applications, Mathematics Supervisors, Secondary Stage.
\end{abstract}

DOI: $10.7176 / \mathrm{JEP} / 12-31-03$

Publication date: November $30^{\text {th }} 2021$

\subsection{INTRODUCTION:}

Educators have realized the benefits and advantages of educational technology in the learning and teaching process because of the positive effects that studies and research have proven, and because they have a direct impact and reflection on educational outcomes, and the skills, experiences and knowledge that are equipped effectively, which enables the future generation of learners to encounter challenges and keep pace with the accelerating age of technology- with its different types -which offer a variety of experiences(Alyan and Debs, 1999).

Therefore, educational technology is a cornerstone of the educational process and an integral part of the comprehensive educational system. Perhaps the challenges encountering the world today and the rapid change that occurred in all aspects of life made it necessary and urgent for educational institutions to adapt technology developments by introducing applications that achieve objectives of the educational system (Al-Sharhan, 2000).

Educational technology plays important roles in the educational process, and the most important of which is to achieve the goals of the curriculum effectively. The applications of educational technology have several roles, the first of which is the role that contributes to solve educational problems, such as the sizes of textbooks and the obvious individual differences among learners, and the second role is related to teaching learning processes to increase quantitative and qualitative effectiveness through designing situations that suit needs and take into account individual differences through the use of educational technology and its various applications (Mazen, 2006).

if there is need for effective educational technology for teaching any of the scientific subjects, the need for it is more urgent in teaching the mathematics curriculum due to its being abstract. And its assimilation by the learners requires smooth and tangible presentation. In that vein, teaching mathematics requires an intensive implementation of technological applications in education because this plays an important role in bringing symbols and concepts to a tangible reality, and helps move from sensory to the abstract thinking (Al-Mughirah, (1989).

For the purpose of optimal employment of technological applications in education, the mathematics teacher must be well acquainted with all educational applications and how to use them, and how to choose the appropriate one. Therefore, education in developed countries is based on the importance and optimal benefit of using educational means and applications because they serve as a link between the abstract and the tangible. The National Council of Mathematics Teachers in the United States of America recommended that learners should be 
provided with the opportunity to use educational aids that embody mathematical concepts and facts and help transfer them from the abstract stage to the tangible stage) .

Due to the importance of mathematics and mathematical concepts in our daily and practical life, it was necessary to include technological applications in the curricula that educational institutions teach, so this study aimed to reveal the implementation of educational technology applications by mathematics teachers at the secondary stage from the mathematics teachers' and supervisors' perspective inthesouth of Jordan.

\subsection{THE PROBLEM AND QUESTIONS OF THE STUDY:}

Many international and local exams as (TIMS)have indicated a great weakness among learners, as well as a weakness in mastering basic skills and concepts in mathematics, and to the inability to link knowledge to life, because mathematics is mostlyan applied subject.Through a long experience, the researcher noticed considerable weakness attributed to the abstract nature of mathematics and teachers' inability or lack ofsufficient knowledge to use technology, so it is necessary to integrate technology and its applications in terms of content, activities and evaluation.

So this study was to identify mathematics teachers' implement of educational technology applications at the secondary stage from mathematics teachers' and supervisors' perspective in the south of Jordan.

Therefore, this study came to answer the following questions:

1. Mathematics teachers' implementation of educational technology applications in the schools of the directorates of education in the south of Jordan from the teachers' perspective?

2. Mathematics teachers' implementation of educational technology applications in the schools of directors in the south of Jordan from supervisors' perspective?

3. Was there a difference as to mathematics teachers' implementation of educational technology applications in the schools of directorates of education in south of Jordan from the teachers' perspective according to educational qualifications, gender, and experience?

\subsection{OBJECTIVES OF THE STUDY:}

It seeks to achieve the following goals:

1. Identifying mathematics teachers' implementation of educational technology applications at the secondary stage from mathematics teachers' and supervisors' point of view in the south of Jordan.

2. Revealing the difference in mathematics teachers 'implementation of educational technology applications in the schools of directors of education in the south of Jordan from teachers' perspective according to the difference in academic qualification, gender, and experience?

IMPORTANCE OF THE STUDY:

1. Effective implementation of technological applications in education in government institutions.

2. Assisting decision makers in the Jordanian Ministry of Education by including technological applications in the curricula and following up on their implementation by supervisors.

3. Focusing on the importance and effectiveness of integrating and activating the abstract content through its conveying smoothly to the learner using applications.

\subsection{PROCEDURAL DEFINITIONS:}

- Educational technology applications: It is an integrated process based on the application of a structure of science and knowledge about human learning and the use of human and non-human learning resources that emphasize the learner's activity and individuality with the systems approach to achieve educational goals as well as more effective learning.

- Hynek's definition: Hynek (1984) considers that the basis of educational technology is not learning theories as is the belief of some educators, and that there are two definitions that can be used in defining educational technology::

- Gilbert's definition: Technology is the systematic application of practical knowledge, or organized knowledge for practical purposes.

- Definition of UNESCO: technology of education is a systematic approach for designing, implementing and evaluating the entire educational process according to specific goals stemming from research results in the field of education and human communication, using human and non-human resources in order to make education more effective (or to achieve better and more effective learning).

- American Educational Technology Commission definition: Educational technology is beyond the scope of any medium or tool.

- Secondary stage: It is the educational stage that starts from the first secondary class and ends with the second secondary class, and their ages range from $15-18$ years

- Mathematics supervisors: They are the persons entrusted with supervising, following up, assigning and guiding teachers who teach mathematics curriculum in the directorates of education in south of Jordan for the academic year 2020/2021 AD.

\subsection{LIMITATIONS OF THE STUDY}

- Time limits: This study was applied in the first semester of the academic year 2020/2021. 
- Place limits: This study was limited to the directorates of education in south of Jordan.

- Human limits: limited to secondary school mathematics teachers and supervisors.

- Subject Limits: The extent to which mathematics teachers implement educational technology applications at the secondary stage.

\subsection{THEORETICAL FRAMEWORK}

All modern approaches in education empha size the link between technology and education. There is no doubt that technology accompanies the learner's education, and it is gradual according to the age and mental level so that it takes into account mental abilities, the school stages and takes the optimum advantage of the senses and remains as far as possible from the abstract verbal means. As the learner progresses and develops, the need becomes more for the use of educational technology and its applications that simplify concepts and explain laws and simulation smoothly (Bani Hani, 2010).

\section{The importance of educational technology and its role in the educational process.}

The existence of technology in our life, especially in education, is inevitable to apply in order to commensurate with other fields. Therefore, education witnessed a great breakthrough in the twentieth century, but it is increasingly growing in the current century, especially in e-learning, so private and governmental education institutions competed to find effective means that help the student and provide the appropriate atmosphere for effective creativity in work and study in the future (Al-Sartawi, 2003).

Obstacles to the use of educational technology and its applications (Ishtiwi,Alyan, 2010).

1- Teacher's readiness and experience: It is represented in the teacher's experience and training in the use and preparation of technology applications.

2- Time: This process requires a large amount of time to be integrated into the educational process, which poses a major obstacle.

3- Resistance to change: It is not easy for any teacher to change his method of teaching and change the style he has been working on for years.

4- The lack of resources and various material resources and therefore will not be able to integrate and use applications and technology.

5- Most of the buildings are not ready for educational institutions.

\subsection{PREVIOUS STUDIES:}

(Al-Qahtani,study 1433) aimed at identifying the status quo of using technological innovations by mathematics teachers in teaching the developed curricula from mathematics teachers' and supervisors' perspective. To construct the questionnaire, the researcher relied on four levels related to the implementing technological innovations (supporting the educational environment, planning and implementing the lesson, evaluating learner performance, considering teaching and development of mathematics teachers)to determine the actual situation of implementing technological innovations. The study sample consisted of (62) teachers, and (13) ) educational supervisor in Tabuk schools, and after conducting the field application and statistical treatments, the study found a shortcoming in the performance of mathematics teachers in supporting the educational environment of the classroom to encourage the learner to interact positively, and a shortcoming in employing technological innovations in planning and implementing the lesson and evaluating the learner's performance for the purpose of self-professional development of mathematics teachers. There were also statistically significant differences at the significance level (0.01) attributed to academic qualification and experience in teaching, but there were no differences due to the nature of the profession as far as sample responses were concerned.

(Al-Kasasbeh, 2012) conducted a study aimed at knowing science teachers' implementation of e-learning applications in science education and the implementation obstacles in Karak schools. The study included 238 male and female science teachers. The researcher developed a 91- item questionnaire whose validity and reliability were verified. One of the most prominent results of the study was that science teachers' implementation of e-learning applications was medium, and the most important obstacles that the study identified was the lack of internet service for students, as well as the student's lack of seriousness in e-learning. The results also showed that there were no statistically significant differences at the significance level $(0.05)$ in the means of the degree of science teachers' implementation of e-learning applications ascribed to the variable of academic qualification, years of experience, specialization and gender, while there were statistically significant differences at the significance level (0.05) for the variable of computer knowledge in favor of those with computer experience and knowledge.

\subsection{STUDY METHODOLOGY:}

In order to achieve the study objectives and answer its questions, the descriptive approach was used, being the appropriate approach for this study.

\subsection{STUDY POPULATION:}

The study population consisted of high school mathematics teachers in the directorates of education in south of Jordan (All southern districts). and their number (318) male and female teacher for the academic year (2020/2021), and the study population consisted of all the mathematics supervisors in all directorates of the 
South, whose number is (69) male and female supervisor.

\subsection{STUDY SAMPLE:}

The sample of the study accounted for (23\%)of the study population, which consisted of (116) male and female mathematics teachers in Kerak governorate. who were chosen randomly. Table (1) shows the distribution of the study sample according to the variables, and all the (20) male and female supervisors were approved.

Table (1): Distribution of study sample according to gender variables, educational qualification and years of experience

\begin{tabular}{|c|l|c|}
\hline \multicolumn{1}{|c|}{ Variable } & Category & Number \\
\hline \multirow{2}{*}{ Gender } & Male & 47 \\
\cline { 2 - 3 } & Female & 69 \\
\cline { 2 - 3 } & Total & 116 \\
\hline \multirow{2}{*}{ Qualification } & Bachelor's & 85 \\
\cline { 2 - 3 } & Postgraduate & 31 \\
\cline { 2 - 3 } & Total & 116 \\
\hline \multirow{2}{*}{ Years of Experience } & Less than 5 years old & 23 \\
\cline { 2 - 3 } & $\mathbf{5 - 1 0}$ years & 43 \\
\cline { 2 - 3 } & more than 10 years & 50 \\
\cline { 2 - 3 } & Total & 116 \\
\hline
\end{tabular}

\subsection{STUDY TOOL:}

- The questionnaire was constructed after reviewing the theoretical literature and previous studies related to the subject of the study (Al-Kasasbeh, 2012), Al-Qahtani, 1433).

The questionnaire consisted of two parts:

section One : (Gender, years of experience, educational qualification).

The second section: includes (38) items to measure the extent to which mathematics teachers implement educational technology applications in the secondary stage from the teachers' and supervisors' views The questionnaire was distributed as follows:

- $\quad$ Educational appliances (4) items.

- Models and models (4) items.

- Computer and its applications (13) items.

- Education individualization programs (11) items.

- $\quad$ Interactive boards (6) items.

\subsection{VALIDITY OF THE STUDY TOOL:}

The validity of the internal consistency was verified, and the questionnaire items were applied to a pilot sample consisting of (35) male and female teachers who were randomly selected from the study population and outside its sample in order to calculate the Pearson correlation coefficient for each item and the total score of its domain.

Table (2) shows that

Table (2): Correlation coefficients of the paragraphs of each domain in the total degree

\begin{tabular}{|c|c|c|c|c|c|}
\hline domain & $\begin{array}{c}\text { item } \\
n\end{array}$ & $\begin{array}{c}\text { correlation } \\
\text { coefficient }\end{array}$ & domain & $\begin{array}{c}\text { item } \\
\text { n }\end{array}$ & $\begin{array}{c}\text { correlation } \\
\text { coefficient }\end{array}$ \\
\hline \multirow{5}{*}{$\begin{array}{l}\text { educational } \\
\text { appliances }\end{array}$} & 14 & 0.83 & \multirow{13}{*}{$\begin{array}{l}\text { Computer and its } \\
\text { applications }\end{array}$} & 1 & 0.82 \\
\hline & & & & 2 & 0.86 \\
\hline & 15 & 0.79 & & 3 & 0.52 \\
\hline & 16 & 0.82 & & 4 & 0.66 \\
\hline & 17 & 0.73 & & 5 & 0.65 \\
\hline \multirow{8}{*}{ model } & 18 & 0.92 & & 6 & 0.60 \\
\hline & 19 & 0.64 & & 7 & 0.91 \\
\hline & \multirow[t]{3}{*}{20} & \multirow[t]{3}{*}{0.79} & & 8 & 0.94 \\
\hline & & & & 9 & 0.58 \\
\hline & & & & 10 & 0.58 \\
\hline & \multirow[t]{3}{*}{21} & \multirow[t]{3}{*}{0.73} & & 11 & 0.63 \\
\hline & & & & 12 & 0.60 \\
\hline & & & & 13 & 0.56 \\
\hline \multirow{5}{*}{$\begin{array}{l}\text { Interactive } \\
\text { whiteboards }\end{array}$} & \multirow[t]{2}{*}{33} & \multirow[t]{2}{*}{0.75} & \multirow{5}{*}{$\begin{array}{c}\text { Education Individualization } \\
\text { Programs }\end{array}$} & 22 & 0.87 \\
\hline & & & & 23 & 0.82 \\
\hline & \multirow[t]{2}{*}{34} & \multirow[t]{2}{*}{0.69} & & 24 & 0.56 \\
\hline & & & & 25 & 0.86 \\
\hline & 35 & 0.79 & & 26 & 0.57 \\
\hline
\end{tabular}




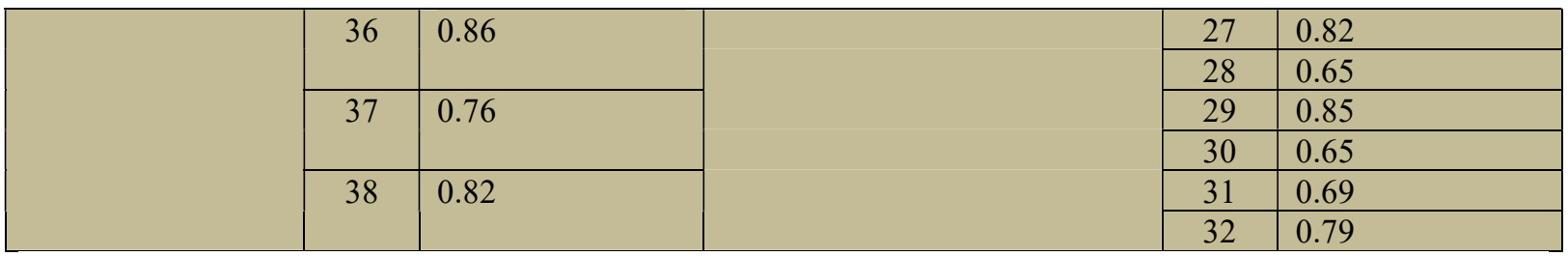

Table (3): the correlation coefficient of each field with the total score of the questionnaire

\begin{tabular}{|l|c|}
\hline \multicolumn{1}{|c|}{ Domain } & Correlation coefficient for each degree \\
\hline 1- Computer and its applications. & 0.61 \\
\hline 2- Educational appliances. & 0.65 \\
\hline 3- Models & 0.57 \\
\hline 4- Education individualization Programs & 0.51 \\
\hline 5- Interactive whiteboards & 0.48 \\
\hline
\end{tabular}

It is clear from the table data that all correlation coefficients are positive and statistically significant at the level of significance $(0.01)$

\subsection{RELIABILITY OF THE STUDY INSTRUMENT:}

The reliability of the questionnaire was verified using the internal consistency coefficient of Cronbach's alpha equation, where the value of the reliability coefficient for the questionnaire as a whole was (0.87), and Table (4) shows the values of the reliability coefficients for each domain.

Table (4): The values of the reliability coefficient for each of the five main domains of the questionnaire

\begin{tabular}{|l|c|}
\hline \multicolumn{1}{|c|}{ Domain } & Correlation coefficient for each degree \\
\hline Computer and its applications. & 0.89 \\
\hline educational appliances. & 0.79 \\
\hline Models & 0.73 \\
\hline Education individualization programs. & 0.89 \\
\hline Interactive whiteboards. & 0.85 \\
\hline Total score & 0.87 \\
\hline
\end{tabular}

The values of the reliability coefficients for each of the five domains ranged between $(0.73-0.89)$ where the value of the reliability of the equation of Cronbach's alpha ( 0.87 ), a high reliability rate.

\subsection{STUDY PROCEDURES:}

1- Reviewing the theoretical literature and previous studies related to the topic.

2- Constructing the study tool in its initial form.

3- Presenting it to a group of arbitrators with expertise and experience.

4- Applying the study tool to a pilot sample to verify the consistency and the validity of the internal consistency.

5- The study tool in its final form after modifications.

6- Applying the study tool by distributing the questionnaire to the study sample.

7- Data collection, tabulation and analysis.

8- Presenting and discussing the results and making recommendations.

\subsection{STUDY VARIABLES:}

The study variables consisted of two types:

1- independent variables:

- Gender: It has two categories (males and females).

- Academic Qualification: It has two categories (Bachelor and Postgraduate studies).

- Years of experience: Three levels (less than 5 years, 5-10 years, 10 years and more).

2- dependent variable:

The extent to which mathematics teachers implement educational technology applications from teachers' and supervisors' perspective.

\subsection{STATISTICAL TREATMENT:}

1- Arithmetic means and standard deviations, the first and second questions.

2- One-way analysis of variance, third question.

\subsection{PRESENTATION AND DISCUSSION OF THE RESULTS.}

1- The results for the first question: To what the extent do mathematics teachers implement educational technology applications in the schools in the directorates of education in south of Jordan from the teachers' point of view?

The arithmetic mean and standard deviation were calculated for each of the domains included in the questionnaire as a whole, and Table (5) illustrates this. 
Table (5): the arithmetic mean and standard deviation of the mathematics teachers' implementation of educational technology applications for the questionnaire as a whole and in all domains

\begin{tabular}{|l|l|l|l|l|}
\hline Domain & $\begin{array}{l}\text { Arithmetic } \\
\text { mean }\end{array}$ & $\begin{array}{l}\text { standard } \\
\text { deviation }\end{array}$ & ranking & implementation \\
\hline models & 3.83 & 0.55 & 1 & High \\
\hline interactive whiteboard & 3.79 & 0.45 & 2 & High \\
\hline $\begin{array}{l}\text { Education Individualization } \\
\text { Programs }\end{array}$ & 3.78 & 0.30 & 3 & High \\
\hline Computer and its applications & 3.65 & 0.38 & 4 & Medium \\
\hline educational appliances & 3.54 & 0.54 & 5 & Medium \\
\hline Total scores & 3.72 & 0.21 & - & High \\
\hline
\end{tabular}

Table (5) shows that the total arithmetic mean of the mathematics teachers 'implementations of educational technology applications in the schools of the directorates in south of Jordan from the teachers' point of view was high with an arithmetic mean (3.72) and a standard deviation (0.21). It is also noted that the mathematics teachers' implementation of the models in schools in the directorates of south Jordan from the teachers' point of view were high with an arithmetic mean (3.83) and a standard deviation (0.55) due to the availability of models. It is noted that the extent to which mathematics teachers implement interactive whiteboard in the schools of the directorates of south of Jordan from the teachers' point of view was high with an arithmetic mean (3.79) and a standard deviation $(0.45)$ due to its availability and ease of use. It also shows that the extent to which mathematics teachers implement education individualization programs in the schools of the directorates of south of Jordan, from the teachers' point of view, was high with an arithmetic mean (3.78) and a standard deviation (0.30) due to its availability, ease of use and production, and effortlessness. It is clear that the extent to which mathematics teachers implement computers and its applications in the schools of the directorates of south of Jordan, from the teachers' perspective was medium, with an arithmetic mean (3.65) and a standard deviation (0.38), due to the lack of technology in all environments and the inability of some to keep pace with the developments. It isnoticed that the extent to which mathematics teachers employ educational appliances in the schools of the directorates of south of Jordan from the teachers' point of view was medium with an arithmetic mean (3.54) and a standard deviation (0.54) due to the lack of educational appliances due to their high price.

First: the domain of computers and Internet applications.

Table (6): The arithmetic mean and standard deviation of the mathematics teachers' implementation of computers and its applications for the Internet in the schools of the directorates of south of Jordan from teachers' perspective

\begin{tabular}{|c|c|c|c|c|}
\hline item n & Arithmetic mean & standard deviation & ranking & employment \\
\hline 1 & 3.82 & 1.03 & 1 & high \\
\hline 8 & 3.80 & 1.37 & 2 & high \\
\hline 5 & 3.80 & 0.88 & 3 & high \\
\hline 4 & 3.77 & 1.06 & 4 & high \\
\hline 2 & 3.73 & 1.02 & 5 & high \\
\hline 3 & 3.70 & 0.96 & 6 & medium \\
\hline 10 & 3.64 & 1.03 & 8 & medium \\
\hline 13 & 3.61 & 1.09 & 9 & medium \\
\hline 6 & 3.61 & 1.29 & 10 & medium \\
\hline 9 & 3.55 & 1.23 & 11 & medium \\
\hline 12 & 3.54 & 1.01 & 12 & medium \\
\hline 11 & 3.51 & 0.37 & 13 & medium \\
\hline 7 & 3.34 & 1.41 & - & medium \\
\hline
\end{tabular}

In table (6),It is noted that that the implementation of the items $(1-6)$ was high from mathematics teachers' perspective, and their mean ranges from $(3.82-3.70)$. This is attributed to the availability of software and its ease of use. While the items with a rank from (7-13) were medium and its arithmetic average is between (3.34 3.64). Despite the use of technology applications, it does not rise to a high degree and is optimal in use in sports and investigative activities, as well as due to the unavailability of software and the difficulty of its production, some of which require a monthly subscription, and this burdens government educational institutions. 
Second: the domain of educational appliances.

Table (7): the arithmetic mean and standard deviation of the extent to which mathematics teachers implement educational appliances in the schools of the directorates of south of Jordan from the teachers' point of view.

\begin{tabular}{|c|c|c|c|c|}
\hline item n & Arithmetic mean & standard deviation & Ranking & Employment \\
\hline 15 & 3.91 & 0.98 & 1 & high \\
\hline 16 & 3.83 & 0.99 & 2 & high \\
\hline 14 & 3.43 & 1.24 & 3 & medium \\
\hline 17 & 2.98 & 1.26 & 4 & medium \\
\hline Total scores & 3.54 & 0.54 & - & medium \\
\hline
\end{tabular}

It is also noted in table (7) that the two items (15 and 16) were with a high degree and with an arithmetic mean that ranged between $(3.91-3.83)$ and a standard deviation of the two items between $(0.98-0.99)$ due to the ease of use and availability. While the items $(14,17)$ were in a medium degree and with an arithmetic average that ranged between $(3.43$ - 2.98) due to the lack of smart devices that can do research and operations for simulation and the lack of constant Internet in the classrooms.

Third: models

Table (8): The arithmetic mean and standard deviation of the mathematics teachers' implementation of models in the schools of the directorates of south of Jordan from teachers 'view.

\begin{tabular}{|c|c|c|c|c|}
\hline Item no. & Arithmetic mean & Standard deviation & Ranking & Implementation \\
\hline 19 & 4.04 & 0.92 & 1 & high \\
\hline 20 & 3.83 & 0.98 & 2 & high \\
\hline 18 & 3.76 & 0.95 & 3 & high \\
\hline 21 & 3.70 & 0.88 & 4 & high \\
\hline Total marks & 3.83 & 0.55 & - & high \\
\hline
\end{tabular}

As is seen in Table (8) all the items were with a high degree and with an arithmetic mean that ranged between $(3.70-4.04)$ and a standard deviation between $(0.88-0.98)$ due to the ease of production, low cost and high effectiveness in motivating learning.

Fourth: individualization of education Programs.

Table (9): The arithmetic mean and standard deviation of the extent to which mathematics teachers implement individualization programs in schools in the directorates of south of Jordan from the teachers' point of view.

\begin{tabular}{|c|c|c|c|c|}
\hline Item no. & Arithmetic mean & Standard deviation & Ranking & Implementation \\
\hline 32 & 4.02 & 0.95 & 1 & high \\
\hline 24 & 3.98 & 0.92 & 2 & high \\
\hline 25 & 3.96 & 0.97 & 3 & high \\
\hline 30 & 3.91 & 0.96 & 4 & high \\
\hline 26 & 3.85 & 0.89 & 6 & high \\
\hline 27 & 3.80 & 1 & 7 & high \\
\hline 23 & 3.79 & 1.16 & 8 & medium \\
\hline 31 & 3.66 & 0.92 & 9 & medium \\
\hline 28 & 3.62 & 0.99 & 10 & medium \\
\hline 29 & 3.47 & 0.92 & - & high \\
\hline
\end{tabular}

As can be seen in table (9), the items (1-7) had a high degree and with an arithmetic mean that ranged between $(4.02-3.79)$ and a standard deviation of the two items between $(0.89-1.16)$ due to the ease of use and availability and feasibility in the classroom. While the items ranked from (8-11) had a medium degree and with an arithmetic average that ranged between (3.47-3.80) due to the shortage of time which forestall making use of some materials that facilitate teaching such as drawings and color images. 
Fifth: interactive whiteboard.

Table (10): The arithmetic mean and standard deviation of the mathematics teachers' implementation of interactive boards in the schools of the directorates of south of Jordan from the teachers' point of view

\begin{tabular}{|c|c|c|c|c|}
\hline Item no. & Arithmetic mean & Standard deviation & Ranking & Implementation \\
\hline 36 & 4.14 & 0.92 & 1 & high \\
\hline 37 & 3.81 & 0.93 & 2 & high \\
\hline 35 & 3.76 & 0.98 & 3 & high \\
\hline 33 & 3.75 & 0.92 & 4 & high \\
\hline 34 & 3.70 & 0.97 & 5 & high \\
\hline 38 & 3.58 & 0.94 & 6 & medium \\
\hline Total marks & 3.79 & 0.45 & - & high \\
\hline
\end{tabular}

It is note dint able (10) that all the items had at a high degree and with an arithmetic average that ranged between $(3.70-4.14)$ and a standard deviation between $(0.98-0.92)$ with the exception of item No. (38) which had a medium degree, an arithmetic mean (3.58) and a standard deviation (0.94). This provides conclusive and realistic evidence of the use of aids, especially interactive whiteboards which are available and practical.

2- The results related to the second question and their discussion.

To what extent do mathematics teachers implement educational technology applications in the schools of directorate in south of Jordan from the supervisors' perspective?

The arithmetic mean and standard deviation were calculated for each domain of the questionnaire as a whole, and the table (11) illustrates this.

Table (11): the arithmetic mean and standard deviation of the mathematics teachers' implementation of educational applications on the domains of the questionnaire from supervisors' perspective

\begin{tabular}{|l|c|c|c|c|}
\hline Domain & $\begin{array}{c}\text { Arithmetic } \\
\text { mean }\end{array}$ & $\begin{array}{c}\text { Standard } \\
\text { deviation }\end{array}$ & Ranking & implementation \\
\hline models & 2.74 & 0.53 & 1 & medium \\
\hline interactive whiteboard & 2.54 & 0.47 & 2 & medium \\
\hline $\begin{array}{l}\text { Education Individualization } \\
\text { Programs }\end{array}$ & 2.49 & 0.47 & 3 & medium \\
\hline Computer and its applications & 2.33 & 0.36 & 4 & Low \\
\hline educational equipment & 2.24 & 0.66 & 5 & Low \\
\hline Total scores & 2.47 & 0.25 & - & medium \\
\hline
\end{tabular}

Table (11) shows that the arithmetic mean of the mathematics teachers 'implementation of technology applications in education from the supervisors' point of view was medium with an arithmetic mean (2.47) and a standard deviation of (0.25). Therefore, there was unanimous opinion among the supervisors that mathematics teachers' implementation of educational technology applications in the educational process with regard to models had a medium degree, due to their availability, ease of use, and display. Likewise, making advantage of interactive white boardsserves its purpose through the acceptable implementation and had a medium degree.

First: the domain of computers and its applications.

Table (12): The arithmetic mean and standard deviation of the mathematics teachers' implementation of computers and its applications for the Internet in the schools of the directorates in south of Jordan from thesupervisors' point of view.

\begin{tabular}{|c|c|c|c|c|}
\hline Item no. & arithmetic mean & standard deviation & Ranking & implementation \\
\hline 5 & 2.95 & 1.43 & 1 & medium \\
\hline 6 & 2.55 & 1.19 & 2 & medium \\
\hline 10 & 2.55 & 1.19 & 3 & medium \\
\hline 12 & 2.45 & 1.15 & 4 & medium \\
\hline 11 & 2.35 & 1.09 & 5 & medium \\
\hline 4 & 2.30 & 1.26 & 6 & Low \\
\hline 9 & 2.25 & 1.12 & 7 & Low \\
\hline 1 & 2.25 & 1.07 & 9 & Low \\
\hline 3 & 2.20 & 1.11 & 10 & Low \\
\hline 2 & 2.15 & 0.93 & 11 & Low \\
\hline 7 & 2.15 & 1.23 & 12 & Low \\
\hline 13 & 2.10 & 1.02 & 13 & Low \\
\hline 8 & 2.05 & 1.15 & - & Low \\
\hline
\end{tabular}


Table (12) shows that the total score was low with an arithmetic mean of technology applications from the supervisors' point of view (2.33) and a standard deviation of (0.36). items (1-5) had an arithmetic average that ranged between (2.35-2.95) and were of a medium degree, because it is easy to use and time and effort saving and effort in communication, and convenient to use by the teacher. While paragraphs (6-13) had an arithmetic average (2.05-2.30) which is a low degree.

Second, educational appliances:

Table (13): The arithmetic mean and standard deviation of the mathematics teachers 'implementation of educational appliances in the schools of the directorates in south of Jordan from the point of view of supervisors.

\begin{tabular}{|c|c|c|c|c|}
\hline Item no. & Arithmetic mean & Standard deviation & Ranking & Implementation \\
\hline 14 & 2.95 & 1.43 & 1 & medium \\
\hline 15 & 2.15 & 0.99 & 2 & Low \\
\hline 16 & 2.05 & 1.10 & 3 & Low \\
\hline 17 & 1.80 & 0.77 & 4 & Low \\
\hline Total score & 2.24 & 0.66 & - & Low \\
\hline
\end{tabular}

Table (13) shows that the total score had an arithmetic mean (2.24) and a standard deviation (0.66). The items from (2-4) with an arithmetic mean of (1.80-2.15) was low, while item (14) had an arithmetic mean (2.95) with a medium employment degree. This is due to the schools' lack of necessary devices and equipment such as data show.

Third: models.

Table (14): Arithmetic mean and standard deviation of the extent to which mathematics teachers are employed for models and models in the schools of the directorates of southern Jordan from the point of view of the supervisors

\begin{tabular}{|c|c|c|c|c|}
\hline Item no. & arithmetic mean & standard deviation & Ranking & implementation \\
\hline 19 & 3.10 & 1.02 & 1 & medium \\
\hline 20 & 2.25 & 1.02 & 2 & Low \\
\hline 18 & 2.45 & 1.15 & 3 & medium \\
\hline 21 & 3.15 & 0.88 & 4 & medium \\
\hline Total score & 2.74 & 0.53 & - & medium \\
\hline
\end{tabular}

Table (14) shows that the total score is medium with an arithmetic mean (2.74) and a standard deviation (0.53). item (1-3) had a mean of (2.45 - 3.15). The implementation of models was medium because they are portable and convenient, as well as they are easy to produce. While item (20) had an arithmetic average (2.25), the extent of implementation was low and this is due to the fact that mathematics teachers did not implement to a large extent and used it only with drawings.

Fourth: Education Individualization Programs.

Table (15): The arithmetic mean and standard deviation of the mathematics teachers 'implementation of individualization education programs in the schools of the directorates in south of Jordan from the supervisors' point of view

\begin{tabular}{|c|c|c|c|c|}
\hline item no. & arithmetic mean & standard deviation & Ranking & implementation \\
\hline 23 & 3.45 & 1.05 & 1 & medium \\
\hline 28 & 3.20 & 1.58 & 2 & medium \\
\hline 26 & 3.10 & 1.29 & 3 & medium \\
\hline 30 & 2.50 & 1.40 & 4 & medium \\
\hline 22 & 2.45 & 0.99 & 5 & medium \\
\hline 24 & 2.45 & 1.15 & 6 & medium \\
\hline 27 & 2.35 & 1.31 & 7 & medium \\
\hline 31 & 2.25 & 1.02 & 8 & Low \\
\hline 25 & 2.20 & 1.24 & 9 & Low \\
\hline 29 & 2.15 & 1.23 & 10 & Low \\
\hline Total scores & 2.54 & 0.47 & - & medium \\
\hline
\end{tabular}

Table (15) shows that the implementation was at a medium degree, with a mean (2.54) and a standard deviation (0.47). items (1-7) had a mean that ranged between $(2.35-3.45)$ and was medium due to the fact that the mathematics teacher cannot dispense with wooden tools in the teaching process. The items (8-11) had an arithmetic mean that ranged between $(1.80)-2.25)$ It was with a low level of implementation due to the teacher's inability to use tools and programs because of the lack of class time. 
Fifth: interactive whiteboards.

Table (16): The arithmetic mean and standard deviation of the mathematics teachers' implementation of interactive boards in the schools of the directorates of southern Jordan from the point of view of supervisors

\begin{tabular}{|c|c|c|c|c|}
\hline Item no. & arithmetic mean & standard deviation & Ranking & implementation \\
\hline 36 & 2.70 & 1.08 & 1 & high \\
\hline 34 & 2.65 & 1.14 & 2 & high \\
\hline 35 & 2.60 & 0.88 & 3 & high \\
\hline 37 & 2.50 & 1 & 4 & high \\
\hline 38 & 2.45 & 0.23 & 5 & high \\
\hline 33 & 2.05 & 0.83 & 6 & medium \\
\hline Total scores & 2.49 & 0.47 & - & high \\
\hline
\end{tabular}

Table (16) shows that the implementation was medium, with a mean of (2.49) and a standard deviation of (0.47). As the items ranked (1-5) had an arithmetic average that ranged between (2.45-2.70), and it was at a medium degree due to its availability, ease of use and optimal preparation by the teacher, while item (33) had an arithmetic average (2.05) and it was with a low implementation attributed to the whiteboard damage due to repeated use and fall more than once during teaching.

The results related the third question :was there a difference in mathematics teachers 'implementation of educational technology applications in the schools of the directorates in south of Jordan from the teachers' point of view according to educational qualifications, gender, and experience?

To answer the question, the arithmetic mean and standard deviation were calculated for the mathematics teacher's implementation of technology applications according to gender, educational qualification and teaching experience.

Table (17): Arithmetic mean and standard deviation of the mathematics teachers 'implementation of educational technology applications according to gender, teaching experience and educational qualification

\begin{tabular}{|c|c|c|c|c|}
\hline Gender & Qualification & Years of experience & Arithmetic mean & Standard deviation \\
\hline \multirow[t]{6}{*}{ Male } & \multirow{3}{*}{ Bachelor's } & less than 5 & 3.32 & 0.13 \\
\hline & & $5-10$ & 3.59 & 0.16 \\
\hline & & more than 10 & 3.63 & 0.13 \\
\hline & \multirow[t]{3}{*}{ Postgraduate } & less than 5 & 3.74 & 0.31 \\
\hline & & $5-10$ & 3.75 & 0.27 \\
\hline & & more than 10 & 3.67 & 0.19 \\
\hline \multirow[t]{6}{*}{ Female } & \multirow[t]{3}{*}{ Bachelor's } & less than 5 & 3.67 & 0.22 \\
\hline & & $5-10$ & 3.75 & 0.19 \\
\hline & & more than 10 & 3.67 & 0.24 \\
\hline & \multirow[t]{3}{*}{ Postgraduate } & less than 5 & 3.73 & 0.10 \\
\hline & & $5-10$ & 3.65 & 0.22 \\
\hline & & more than 10 & 3.84 & 0.20 \\
\hline
\end{tabular}

It is evident from Table (17) that there were statistically significant differences among the arithmetic means, so a one-way analysis of variance was conducted, and Table (18) shows the results of the analysis.

Table (18): Results of the analysis of the unilateral variance (gender, teaching experience, educational qualification)

\begin{tabular}{|c|c|c|c|c|c|}
\hline Variance & Sum of squares & Degrees of freedom & Mean squares & ( f) Values & Significance \\
\hline Gender & 0.19 & 1 & 0.19 & 4.79 & 0.19 \\
\hline Qualification & 0.29 & 1 & 0.29 & 7.35 & 0.19 \\
\hline Teaching experience & 0.09 & 2 & 0.04 & 1.08 & 0.19 \\
\hline The error & 4.10 & 104 & 0.04 & - & - \\
\hline Total & 5.05 & 115 & - & - & - \\
\hline
\end{tabular}

a -Gender variable: Table (18) shows that there were statistically significant differences in the mathematics teachers implementation of educational technology applications due to the gender variable, in favor of females (4.79). This is due to the high female motivation towards innovation away from routine and tradition in teaching and towards excellence and distinction.

b-Educational qualification variable: Table (18) shows that there were statistically significant differences in the mathematics teachers' implementation educational technology applications due to the educational qualification variable, which was (7.35) in favor of the postgraduate category. This is due to the fact that technology in teaching was the most applied among postgraduates because they studied these courses and materials at university and enjoyed the skills of optimal application and practice. 
c - The experience in teaching variable: Table (18) shows that there were statistically significant differences in the mathematics teachers implementation of educational technology applications due to the experience in teaching variable, which amounted to (1.08) and in favor of those with more than 10- year experience. This can be ascribed to personal experience and teacher's self- development through mathematics networks, participation in prizes and competitions that require high expertise based on the rank system.

\title{
2.2 RECOMMENDATIONS:
}

1 - Providing government educational institutions with all software and devices that simulate the reality of the curriculum and help teachers for optimal implementation, which is directly reflected on the students' achievement.

2 - Constant supervisory visits to evaluate and follow up and urge the use of educational technology software.

3 - Organizing workshops, specialized courses and programs for some applications related to the mathematics curriculum.

\section{REFERENCES :}

- Ishtiwi, Fawzi and Alyan, Rebhi (2010). Educational Technology (Theory and Practice), 1st Edition, Amman: Dar Safaa for Publishing and Distribution.

- Bani Hani, Waleed (2010). Using and implementation of educational techniques in the classroom, 1st edition, Amman: Scientific Dar Al-Yazouri for Publishing and Distribution.

- Al-Sharhan, Jamal Abdulaziz (2000). The effect of using the computer on the first- secondary students'achievementin the physics course. Research of College of Education, King Saud University, Saudi Arabia.

- Al-Qahtani, Othman Ali (2013). The situation of implementation of technological innovations in teaching mathematics of developed curricula from the teachers' and educational supervisors' point of view in Tabuk educational region. Specialized International Educational Journal, 2(5), 407-430.

- Al-Kasasbeh, Tariq Yassin (2012). The extent to which science teachers employ e-learning applications in science education and the obstacles to their implementation in the schools of Karak educational region. Unpublished Master's Thesis, Mutah University, Jordan.

- Mazen, Hossam Mohamed (2006). Information technology and electronic media. Cairo: The Egyptian Renaissance Library.

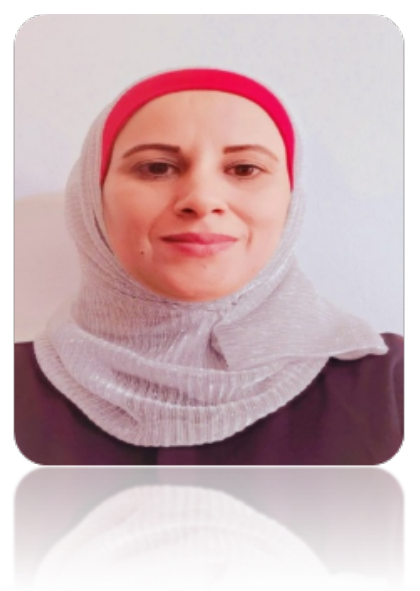

\author{
Ms. HANA HAMAD ABDEL RAHMAN ALLEIMON \\ JORDAN - AL-KARAK \\ Email ID: ziadibrahem80@gmail.com
}

